\title{
Confluent Thalamic Hyperintensities in CADASIL
}

\author{
Mathilde Jacqmin ${ }^{a}$ Dominique Hervé ${ }^{a}$ Anand Viswanathan ${ }^{d}$ \\ Jean-Pierre Guichard ${ }^{b}$ Marco During ${ }^{\mathrm{e}}$ Martin Dichgans ${ }^{\mathrm{e}}$ Hugues Chabriat $^{\mathrm{a}, \mathrm{c}}$ \\ ${ }^{a}$ Service de Neurologie, Centre de référence pour les maladies rares des vaisseaux du cerveau et de l'œil (CERVCO), \\ INSERM U740, CHU Lariboisière, APHP, ${ }^{b}$ Service de Neuroradiologie, CHU Lariboisière, APHP, and ${ }^{c}$ INSERM UMR740, \\ Faculté de Médecine Villemin, Université Denis Diderot, Paris, France; ${ }^{\mathrm{d}}$ Department of Neurology and Clinical Trials \\ Unit, Massachusetts General Hospital and Harvard Medical School, Boston, Mass., USA; 'Department of Neurology, \\ Klinikum Grosshadern, Ludwig Maximilian University, Munich, Germany
}

\section{Key Words}

Thalamus $\cdot \mathrm{CADASIL} \cdot \mathrm{MRI} \cdot \mathrm{T}_{2}$-hyperintensities $\cdot$

Demyelination

\begin{abstract}
Background: CADASIL is responsible for diffuse hyperintensities in the white matter on FLAIR images. These lesions are often associated with focal lesions in the basal ganglia such as lacunar infarctions. The prevalence and significance of diffuse or confluent thalamic hyperintensities (CTH) remain unknown. Methods: The frequency of hyperintensities on FLAIR images in the thalamus was assessed in 147 CADASIL patients, and signal abnormalities on both FLAIR and $T_{1-}$ weighted images were categorized as focal/punctuate or diffuse/confluent by the same reader. The areas of increased diffusion were also analyzed on apparent diffusion coefficient maps. The association of CTH with vascular risk factors, the main clinical manifestations of the disease and MRI markers (brain parenchymal fraction, volume of white matter hyperintensities, volume of lacunar infarcts and number of microbleeds) was analyzed with generalized linear regression models. Results: CTH were detected in $12 \%$ of the CADASIL subjects in association with hypointensities on $\mathrm{T}_{1}$-weighted images. CTH corresponded to areas of increased diffusion on
\end{abstract}

apparent diffusion coefficient maps. CTH were found significantly associated with age and independently related to the volume of white matter hyperintensities but not to that of lacunar infarctions or to cerebral atrophy after adjustment for age and sex. No significant association was found between CTH and global cognitive performances. Conclusion: CTH are observed on FLAIR images in a sizeable proportion of CADASIL patients. They are mainly related to the extent of white matter hyperintensities and do not correlate with cognitive decline. Demyelination and/or loss of glial cells appear to be the most plausible cause of these confluent signal changes in the thalamus.

Copyright $\odot 2010$ S. Karger AG, Basel

\section{Introduction}

The current imaging concepts of small-vessel disease are based on the presence of confluent ischemic lesions in the white matter ('leukoaraiosis') associated with lacunar infarcts. The presence of confluent MRI lesions within the deep grey matter, particularly within the thalamus, is not a rare feature in patients with small-vessel disease (own observations). However, these lesions have received little attention in the literature, and there is no detailed descrip-

\section{KARGER}

Fax +4161306 1234 E-Mail karger@karger.ch www.karger.com

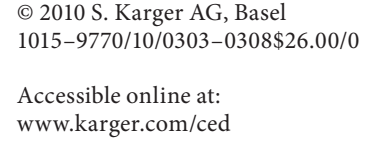

Prof. Hugues Chabriat

Service de Neurologie, Hôpital Lariboisière

2 , rue Ambroise Paré, FR-75010 Paris (France)

Tel. +331 499563 44, Fax +331 49952596

E-Mail hugues.chabriat@lrb.ap-hop-paris.fr 
tion regarding their neuroimaging features, their correlation with other imaging findings and their potential clinical correlates. We set out to provide these informations in Cerebral Autosomal Dominant Arteriopathy with Subcortical Infarcts and Leukoencephalopathy (CADASIL), a model of ischemic small vessel disease caused by mutations of the NOTCH3 gene on chromosome 19 [1-5].

In symptomatic and asymptomatic CADASIL patients, cerebral MRI can show diffuse white matter hyperintensities (WMH) on FLAIR or $\mathrm{T}_{2}$-weighted images [6]. WMH presumably appear during the third decade and are constant after 40 years [7-9]. They are of variable extent, have a symmetrical distribution and initially predominate in the deepest territories of cerebral penetrating arteries. They progressively become confluent and diffuse. WMH are associated with lacunar infarcts which are usually well delineated on FLAIR or 3-dimensional $\mathrm{T}_{1}$-weighted images. $\mathrm{T}_{2}$ or FLAIR hyperintensities are also observed in basal ganglia and within the brainstem [10]. Microbleeds and dilated perivascular spaces are also frequently detected [11-14].

In the deep grey nuclei of CADASIL patients, most signal abnormalities have been reported as focal or punctiform lesions that usually correspond either to dilated perivascular spaces or to lacunar infarctions. They are hyperintense on $\mathrm{T}_{2}$-weighted images and hypointense on $\mathrm{T}_{1}$-weighted images. Only in anecdotal reports have diffuse signal abnormalities distinct from these focal lesions been described in the central grey matter on $\mathrm{T}_{2}$-weighted or FLAIR images, mostly within the thalamus $[8,15]$. The frequency of thalamic confluent lesions and their relationship with the other MRI markers of the disease are unknown. In addition, their clinical significance and potential impact on cognition has not been evaluated [16].

In this study, we determined the frequency of signal abnormalities in thalamic nuclei as seen on $\mathrm{T}_{1}$ and FLAIR images and on apparent diffusion coefficient (ADC) maps in a large population of CADASIL patients. We described the main characteristics of diffuse or confluent thalamic hyperintensities (CTH) as observed on FLAIR images in patients with CADASIL.

\section{Material and Methods}

\section{Subjects}

Data were obtained from an ongoing multicenter prospective cohort study of subjects with CADASIL. A total of 147 patients were enrolled into the study at the Lariboisière hospital (Paris) and at the Ludwig Maximilian University (Munich) between 2003 and 2005. The complete study design has been detailed elsewhere [17].
Magnetic Resonance Imaging

MRI scans were performed by the use of a 1.5-tesla system [Vision, Siemens (Munich) or Signa General Electric Medical Systems (Paris)]. $\mathrm{T}_{1}$-weighted axial sequences, FLAIR, $\mathrm{T}_{2}{ }^{*}$-weighted GE planar imaging and diffusion-weighted imaging were performed. The protocol parameters have been previously detailed [17].

Image Processing and Analysis

The total volume of $\mathrm{WMH}$, lacunes and brain parenchymal fraction defined as the ratio of brain tissue volume to total intracranial cavity volume was assessed as previously described [17, 18].

A qualitative visual scale was used by a neurologist blinded to clinical data (M.J.). The following characteristics were rated for each scan in the thalamus: (1) presence or absence of hyperintensities on FLAIR images, (2) presence or absence of hypointensities on $\mathrm{T}_{1}$-weighted images, (3) focal or punctuate versus diffuse or confluent hyperintensities (CTH), (4) visible increase in diffusion on ADC maps in areas corresponding to $\mathrm{CTH}$, and (5) presence or absence of microbleeds on $\mathrm{T}_{2}{ }^{*}$-weighted images. The presence or absence of hyperintensities was also systematically assessed on FLAIR images in the internal capsule, the caudate nuclei and the putamen.

\section{Statistical Methods}

In this study, 145 cerebral MRIs were analyzed. In addition, 20 randomized MRIs were used to estimate the intra- and interobserver reliability of the visual scale. $\kappa$ statistics were used and interpreted according to the Landis and Koch scale [19]. The reliability for detection of thalamic signal abnormalities on FLAIR images (as assessed by M.J. and D.H.) was excellent (intrarater agreement, $\kappa=0.78$; interrater agreement, $\kappa=0.76$ ). The intrarater agreement for categorization of thalamic lesions as focal/ punctuate or confluent/diffuse was also excellent $(\kappa=0.89)$, and the interrater agreement for categorization was substantial $(\kappa=$ $0.65)$.

The clinical and demographic characteristics and distribution of cerebral MRI parameters were described using $\chi^{2}$ test for categorial variables and Student's t test or analysis of variance for continuous variables. Regression models were used to evaluate the factors associated with CTH. Covariates with a $\mathrm{p}$ value $>0.2$ in univariate analysis were introduced in the multivariate models in addition to potential confounding factors. Generalized linear regression models were used to study the relationships between $\mathrm{CTH}$ and cerebral lesion volumes. All models were adjusted for age and sex. Significance was considered when the $p$ values were $<0.05$. All statistical tests were performed with SAS 9.1.

\section{Results}

\section{Main Characteristics of the Population}

The men were older than the women at the time of MRI examination (52 vs. 48 years, $\mathrm{p}=0.03$ ). In univariate analysis, the vascular risk factors and main clinical characteristics of the disease did not differ between these two groups. All subjects (mean age $\pm \mathrm{SD}=52 \pm 11$ years) 
Table 1. Main clinical characteristics of the population

\begin{tabular}{lc}
\hline Characteristics & \\
\hline Mean age, years & $52 \pm 11$ \\
Hypertension & $26(18)$ \\
Hypercholesterolemia & $62(43)$ \\
Diabetes & $3(2)$ \\
Past or current smoker & $72(50)$ \\
Body mass index $>25$ & $66(45)$ \\
Mood disorders & $69(47)$ \\
Migraine with aura & $70(48)$ \\
History of stroke or TIA & $99(69)$ \\
Dementia & $22(15)$ \\
\hline
\end{tabular}

Total $=145$. Figures are means \pm SD or numbers of cases with percentages in parentheses. TIA $=$ Transient ischemic attack. presented with MRI signal abnormalities (table 1), including WMH in all subjects, lacunar infarctions in $92 \%$ $(\mathrm{n}=129)$ and microbleeds in $35 \%(\mathrm{n}=51)$.

\section{Frequency of Confluent/Diffuse Thalamic Signal}

Abnormalities

CTH were observed in $12 \%$ of the patients $(n=17)$ on FLAIR images as shown in table 2. All patients with CTH had superimposed thalamic hypointensities on $\mathrm{T}_{1^{-}}$ weighted images.

The visual examination revealed that, in the presence of $\mathrm{CTH}$, an increase in diffusion was detected on ADC maps in $82 \%$ of the cases $(n=14)$. A strip-like aspect was detected in 3 cases, always in the presence of ipsilateral hyperintense lesions located in the internal capsule. Figure 1 shows different patterns of CTH in 6 patients.

In the whole cohort, punctuate or focal hyperintensities in the thalamus were detected on FLAIR images in $34 \%$ of the subjects $(n=49)$. On $T_{2}{ }^{*}$-weighted images, microbleeds were found in the thalamus in $12 \%$ of the patients $(\mathrm{n}=18)$.

\section{Relationships between CTH and the Main Clinical or MRI Parameters}

Univariate analysis showed that $\mathrm{CTH}$ were associated with age $(p=0.002)$ but not with the presence of vascular risk factors, nor with any of the main clinical manifestations of the disease (table 2). In addition, no significant association was found between CTH and the Mattis Dementia Rating scale after adjustment for age and sex $(130.4 \pm 2.8$ vs. $139 \pm 4.8, \mathrm{p}=0.12)$. While $\mathrm{CTH}$ were
Table 2. Main clinical characteristics of the disease in the presence or absence of CTH

\begin{tabular}{lccl}
\hline Main clinical characteristics & CTH - & CTH + & $\mathrm{p}$ \\
\hline Number & $128(88)$ & $17(12)$ & \\
Male sex & $56(44)$ & $7(41)$ & 0.84 \\
Age, years & $50.9 \pm 10.9$ & $59.4 \pm 7.8$ & 0.002 \\
Hypertension & $24(19)$ & $2(12)$ & 0.47 \\
Hypercholesterolemia & $55(43)$ & $7(41)$ & 0.87 \\
Diabetes & $3(2.4)$ & $0(0)$ & 0.52 \\
Past or current smoker & $67(52)$ & $5(29)$ & 0.08 \\
Body mass index $>25$ & $59(46)$ & $7(41)$ & 0.70 \\
Mood disorders & $62(49)$ & $7(41)$ & 0.44 \\
Migraine with aura & $63(49)$ & $7(41)$ & 0.53 \\
History of TIA or stroke & $87(69)$ & $12(71)$ & 0.89 \\
Dementia & $19(15)$ & $3(18)$ & 0.79 \\
\hline
\end{tabular}

Figures are means \pm SD or numbers of cases with percentages in parentheses. TIA $=$ Transient ischemic attack.

Table 3. Association between CTH and the other MRI markers of the disease

\begin{tabular}{llll}
\hline & CTH- & CTH+ & $\mathrm{p}$ \\
\hline $\begin{array}{l}\text { Univariate analysis } \\
\text { WMH volume }\end{array}$ & $7.32(0.40)$ & $9.76(1.10)$ & 0.04 \\
Lacunar volume & $0.09(0.01)$ & $0.08(0.04)$ & 0.81 \\
BPF & $80.1(0.49)$ & $83.5(1.35)$ & 0.02 \\
\hline Multivariate analysis & & & \\
WMH volume & $6.92(0.41)$ & $9.56(1.12)$ & 0.03 \\
Lacunar volume & $0.07(0.01)$ & $0.07(0.02)$ & 0.91 \\
BPF & $80.4(0.48)$ & $82.8(1.34)$ & 0.09 \\
\hline
\end{tabular}

Univariate and multivariate analyses after adjustment for age and sex. Figures are means with standard errors in parentheses. $\mathrm{BPF}=$ Brain parenchymal fraction.

found to be significantly associated with the volume of $\mathrm{WMH}$ and with the brain volume in univariate analysis, multivariate models showed that, among the different MRI markers, CTH were only related to $\mathrm{WMH}(\mathrm{p}=0.03)$ after adjustment for age and sex (table 3 ). Univariate analysis showed that CTH were also associated with the presence of hyperintensities in the internal capsule $(\mathrm{OR}=5.2$; $95 \% \mathrm{CI}=1.2-22.3)$, in the caudate nuclei $(\mathrm{OR}=7.9 ; 95 \%$ $\mathrm{CI}=1.3-47)$ and within the putamen $(\mathrm{OR}=11.4 ; 95 \%$ $\mathrm{CI}=3.0-43.4)$. 


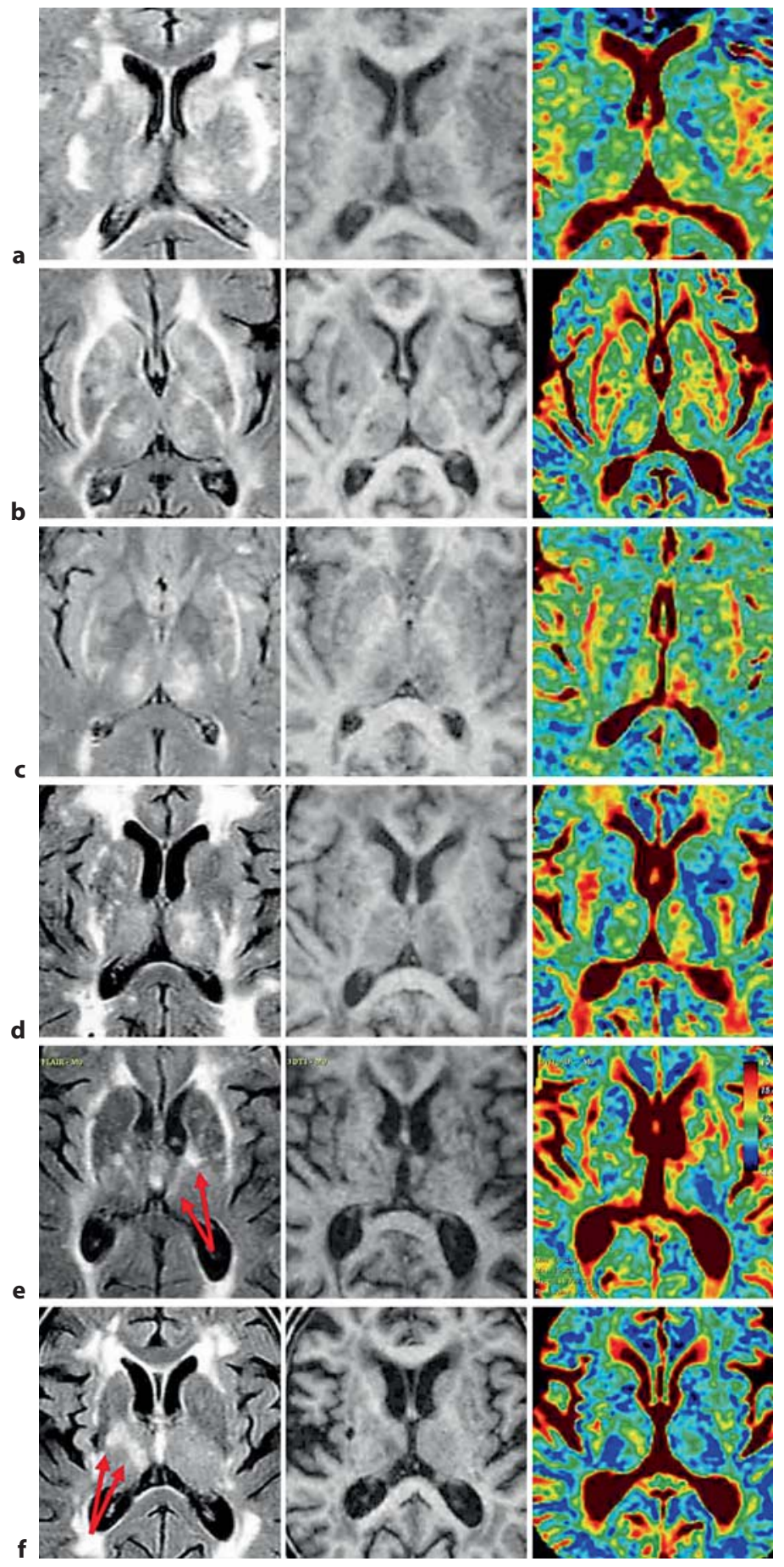

Fig. 1. Axial MRI slices showing various patterns of diffuse or confluent signal abnormalities in the thalamus in CADASIL patients. From left to right: FLAIR images, $\mathrm{T}_{1}$-weighted images and ADC maps are shown. Different patterns of MR signal abnormalities are detected in the thalamus: more or less diffuse hyperintensities are visible on FLAIR images corresponding to a superimposed area of increased diffusion on ADC maps, in the absence of focal hypointensities suggestive of lacunar infarctions on $\mathrm{T}_{1^{-}}$ weighted images (subjects a-d); confluent but more limited hy-

\section{Discussion}

Among 145 patients with CADASIL, we observed that $12 \%$ presented with confluent or diffuse hyperintensities in the thalamus on FLAIR images. These signal abnormalities were found to be associated with age and with the volume of WMH but not with the load of lacunar infarctions, number of microbleeds or with cerebral atrophy. These findings suggest that CTH are more related to the extent of leukoaraiosis than to the accumulation of focal ischemic lesions or to global cerebral tissue loss in CADASIL patients. The lack of a relationship between $\mathrm{CTH}$ and clinical severity is also in line with recent data indicating that the extent of $\mathrm{WMH}$, in contrast to the load of lacunar infarctions and degree of cerebral atrophy, does not have a significant and independent impact on the severity of cognitive decline in this disorder [20,21].

The pathological lesions underlying CTH are still unknown. A plausible hypothesis is that CTH are mainly related to diffuse demyelination within the thalamus. Diffuse thalamic $\mathrm{T}_{2}$ hyperintensities as observed in the present study have been previously reported in pure dysmyelinating disorders such as in maple syrup urine disease [22]. Demyelination is also a common feature in leukoaraiosis [23] and has been reported in the white matter as well as in subcortical grey matter in CADASIL patients $[24,25]$. Molko et al. [26, 27] previously observed an early increase in diffusion and decrease in anisotropy in the thalamus of 20 CADASIL patients that is also compatible with a loss of orientated myelin fibers. In the present study, we observed a similar increase in thalamic diffusion overlapping the diffuse or confluent MRI thalamic signal changes.

Other mechanisms may also play a role. Diffuse reduction in glial cells in the thalamus as already reported in animal models of chronic ischemia may contribute to $\mathrm{CTH}$ [28]. Wallerian degeneration after focal ischemic lesions in thalamofugal or thalamopetal fibers may be implicated $[26,29]$. The observation of a strip-like aspect in

perintensities with a strip-like aspect on FLAIR images are detected in patient $\mathbf{e}$ and in patient $\mathbf{f}$. Note that strip-like lesions were observed in the thalamus in patients $\mathbf{e}$ and $\mathbf{f}$ in the presence of ipsilateral hyperintense lesions within the internal capsule (suggestive of wallerian degeneration of intrathalamic myelin fibers red arrows). 
some cases of $\mathrm{CTH}$ in relation to an ipsilateral lesion in the internal capsule are in support of this latter hypothesis. Other underlying processes cannot be excluded. Particularly, an increased number of dilated perivascular spaces, a frequent pathological feature of CADASIL, is also a potential source of confluent $\mathrm{T}_{2}$ hyperintensities [30]. However, both the location and distribution of signal changes with the diffuse pattern and/or a strip-like aspect seem unlikely to be related to such a process.

This study has several limitations. We analyzed only diffuse or confluent signal changes in the thalamus and not in the other grey nuclei. This choice was made because the reliability of visual analysis of signal changes within the putamen or in the caudate nuclei on FLAIR images was much less satisfactory than within the thalamus (data not shown). The frequent association of dilated perivascular spaces and lacunar infarctions in the putamen or caudate nuclei is mainly responsible for this discrepancy. Because we performed the study based on FLAIR images with a specific sequence, we cannot exclude a different frequency of CTH using other MRI parameters (such as $\mathrm{T}_{2}$-weighted or proton density images).
Finally, the analysis was based on visual examination but not on quantitative data in the thalamus.

In conclusion, diffuse and confluent hyperintensities are observed on FLAIR images in the thalamus in $>10 \%$ of the CADASIL patients. These MRI signal changes are associated with water diffusion increase that presumably reflects significant underlying microstructural changes. The association with WMH but not with the other MRI markers as well as the topographic distribution of signal changes suggests that demyelination is most likely related to CTH. Whether chronic ischemia is responsible for diffuse demyelination or glial cell loss underlying CTH will require further investigation.

\section{Acknowledgements}

This work was supported by PHRC grant AOR 02-001 (DRC/ APHP) and performed with the help of ARNEVA (Association de Recherche en Neurologie Vasculaire), Hôpital Lariboisière, France, and under the corporate patronage of the Bouygues Company.

\section{References}

1 Joutel A, Corpechot C, Ducros A, Vahedi K, Chabriat $\mathrm{H}$, Mouton $\mathrm{P}$, Alamowitch S, Domenga V, Cecillion M, Marechal E, Maciazek J, Vayssiere C, Cruaud C, Cabanis EA, Ruchoux MM, Weissenbach J, Bach JF, Bousser MG, Tournier-Lasserve E: Notch3 mutations in CADASIL, a hereditary adultonset condition causing stroke and dementia. Nature 1996;383:707-710.

2 Tournier-Lasserve E, Joutel A, Melki J, Weissenbach J, Lathrop GM, Chabriat H, Mas JL, Cabanis EA, Baudrimont M, Maciazek J, et al: Cerebral autosomal dominant arteriopathy with subcortical infarcts and leukoencephalopathy maps to chromosome 19q12. Nat Genet 1993;3:256-259.

3 Ruchoux MM, Brulin P, Brillault J, Dehouck MP, Cecchelli R, Bataillard M: Lessons from CADASIL. Ann NY Acad Sci 2002;977:224231.

4 Ruchoux MM, Maurage CA: Endothelial changes in muscle and skin biopsies in patients with CADASIL. Neuropathol Appl Neurobiol 1998;24:60-65.

5 Joutel A, Favrole P, Labauge P, Chabriat H, Lescoat C, Andreux F, Domenga V, Cecillon M, Vahedi K, Ducros A, Cave-Riant F, Bousser MG, Tournier-Lasserve E: Skin biopsy immunostaining with a notch 3 monoclonal antibody for CADASIL diagnosis. Lancet 2001;358:2049-2051.
6 Dichgans M: CADASIL: A monogenic condition causing stroke and subcortical vascular dementia. Cerebrovasc Dis 2002;13(suppl 2):37-41.

7 van den Boom R, Lesnik Oberstein SA, Ferrari MD, Haan J, van Buchem MA: Cerebral autosomal dominant arteriopathy with subcortical infarcts and leukoencephalopathy: MR imaging findings at different ages - 3rd6th decades. Radiology 2003;229:683-690.

8 Chabriat H, Levy C, Taillia H, Iba-Zizen MT, Vahedi K, Joutel A, Tournier-Lasserve E, Bousser MG: Patterns of MRI lesions in CADASIL. Neurology 1998;51:452-457.

9 Chabriat H, Joutel A, Dichgans M, TournierLasserve E, Bousser MG: CADASIL. Lancet Neurol 2009;8:643-653.

10 Chabriat H, Mrissa R, Levy C, Vahedi K, Taillia H, Iba-Zizen MT, Joutel A, TournierLasserve E, Bousser MG: Brain stem MRI signal abnormalities in CADASIL. Stroke 1999;30:457-459.

11 Cumurciuc R, Guichard JP, Reizine D, Gray F, Bousser MG, Chabriat H: Dilation of Virchow-Robin spaces in CADASIL. Eur J Neurol 2006;13:187-190.
12 Viswanathan A, Chabriat H: Cerebral microhemorrhage. Stroke 2006;37:550-555.

13 Dichgans M, Holtmannspotter M, Herzog J, Peters N, Bergmann M, Yousry TA: Cerebral microbleeds in CADASIL: a gradient-echo magnetic resonance imaging and autopsy study. Stroke 2002;33:67-71.

14 Choi JC, Kang SY, Kang JH, Park JK: Intracerebral hemorrhages in CADASIL. Neurology 2006;67:2042-2044.

15 Auer DP, Putz B, Gossl C, Elbel G, Gasser T, Dichgans M: Differential lesion patterns in CADASIL and sporadic subcortical arteriosclerotic encephalopathy: MR imaging study with statistical parametric group comparison. Radiology 2001;218:443-451.

16 O'Sullivan M, Singhal S, Charlton R, Markus HS: Diffusion tensor imaging of thalamus correlates with cognition in CADASIL without dementia. Neurology 2004;62:702-707.

17 Viswanathan A, Guichard JP, Gschwendtner A, Buffon F, Cumurcuic R, Boutron C, Vicaut E, Holtmannspotter M, Pachai C, Bousser MG, Dichgans M, Chabriat H: Blood pressure and haemoglobin $A_{1 c}$ are associated with microhaemorrhage in CADASIL: a two-centre cohort study. Brain 2006;129: 2375-2383. 
18 Jouvent E, Viswanathan A, Mangin JF, O'Sullivan M, Guichard JP, Gschwendtner A, Cumurciuc R, Buffon F, Peters N, Pachai C, Bousser MG, Dichgans M, Chabriat H: Brain atrophy is related to lacunar lesions and tissue microstructural changes in CADASIL. Stroke 2007;38:1786-1790.

19 Landis JR, Koch GG: The measurement of observer agreement for categorical data. Biometrics 1977;33:159-174.

20 Viswanathan A, Gschwendtner A, Guichard JP, Buffon F, Cumurciuc R, O'Sullivan M, Holtmannspotter M, Pachai C, Bousser MG, Dichgans M, Chabriat H: Lacunar lesions are independently associated with disability and cognitive impairment in CADASIL. Neurology 2007;69:172-179.

21 Liem MK, van der Grond J, Haan J, van den Boom R, Ferrari MD, Knaap YM, Breuning $\mathrm{MH}$, van Buchem MA, Middelkoop HA, Lesnik Oberstein SA: Lacunar infarcts are the main correlate with cognitive dysfunction in CADASIL. Stroke 2007;38:923-928.
22 Schonberger S, Schweiger B, Schwahn B, Schwarz M, Wendel U: Dysmyelination in the brain of adolescents and young adults with maple syrup urine disease. Mol Genet Metab 2004;82:69-75.

23 Kelley RE: Ischemic demyelination. Neurol Res 2006;28:334-340.

24 Ruchoux MM, Domenga V, Brulin P, Maciazek J, Limol S, Tournier-Lasserve E, Joutel A: Transgenic mice expressing mutant notch3 develop vascular alterations characteristic of cerebral autosomal dominant arteriopathy with subcortical infarcts and leukoencephalopathy. Am J Pathol 2003;162: 329-342.

25 Ruchoux MM, Maurage CA: CADASIL: Cerebral Autosomal Dominant Arteriopathy with Subcortical Infarcts and Leukoencephalopathy. J Neuropathol Exp Neurol 1997;56: 947-964.

26 Molko N, Pappata S, Mangin JF, Poupon C, Vahedi K, Jobert A, LeBihan D, Bousser MG, Chabriat $\mathrm{H}$ : Diffusion tensor imaging study of subcortical gray matter in CADASIL. Stroke 2001;32:2049-2054.
27 Molko N, Pappata S, Mangin JF, Poupon F, LeBihan D, Bousser MG, Chabriat H: Monitoring disease progression in CADASIL with diffusion magnetic resonance imaging: a study with whole brain histogram analysis. Stroke 2002;33:2902-2908.

28 Tomimoto H, Ihara M, Wakita H, Ohtani R, Lin JX, Akiguchi I, Kinoshita M, Shibasaki $\mathrm{H}$ : Chronic cerebral hypoperfusion induces white matter lesions and loss of oligodendroglia with DNA fragmentation in the rat. Acta Neuropathol 2003;106:527-534.

29 Tatsch K, Koch W, Linke R, Poepperl G, Peters N, Holtmannspoetter M, Dichgans M: Cortical hypometabolism and crossed cerebellar diaschisis suggest subcortically induced disconnection in CADASIL: an 18FFDG pet study. J Nucl Med 2003;44:862-869.

30 Yamamoto Y, Ihara M, Tham C, Low RW, Slade JY, Moss T, Oakley AE, Polvikoski T, Kalaria RN: Neuropathological correlates of temporal pole white matter hyperintensities in CADASIL. Stroke 2009;40:2004-2011. 